ORIGINAL ARTICLE

\title{
Pedestrian crashes: higher injury severity and mortality rate for light truck vehicles compared with passenger vehicles
}

\author{
B S Roudsari, C N Mock, R Kaufman, D Grossman, B Y Henary, J Crandall
}

Injury Prevention 2004;10:154-158. doi: 10.1136/ip.2003.003814

See end of article for authors' affiliations

Correspondence to Dr Bahman S Roudsari, Harborview Injury Prevention and Research Center, 325 9th Ave, Seattle, WA 98104-2499, USA; roudsari@u. washington.edu
Introduction: During the last two decades changes in vehicle design and increase in the number of the light truck vehicles (LTVs) and vans have led to changes in pedestrian injury profile. Due to the dynamic nature of the pedestrian crashes biomechanical aspects of collisions can be better evaluated in field studies. Design and settings: The Pedestrian Crash Data Study, conducted from 1994 to 1998, provided a solid database upon which details and mechanism of pedestrian crashes can be investigated.

Results: From 552 recorded cases in this database, 542 patients had complete injury related information, making a meaningful study of pedestrian crash characteristics possible. Pedestrians struck by LTVs had a higher risk $(29 \%)$ of severe injuries (abbreviated injury scale $\geqslant 4$ ) compared with passenger vehicles $(18 \%)$ $(p=0.02)$. After adjustment for pedestrian age and impact speed, LTVs were associated with 3.0 times higher risk of severe injuries $(95 \%$ confidence interval $(\mathrm{CI}) 1.26$ to $7.29, p=0.013)$. Mortality rate for pedestrians struck by LTVs $(25 \%)$ was two times higher than that for passenger vehicles $(12 \%)(p<0.001)$. Risk of death for LTV crashes after adjustment for pedestrian age and impact speed was 3.4 times higher than that for passenger vehicles $(95 \% \mathrm{Cl} 1.45$ to $7.81, \mathrm{p}=0.005)$.

Conclusion: Vehicle type strongly influences risk of severe injury and death to pedestrian. This may be due in part to the front end design of the vehicle. Hence vehicle front end design, especially for LTVs, should be considered in future motor vehicle safety standards.
C hanges in vehicle design and composition of the vehicle fleet during the past two decades have resulted in changes in injury profile among pedestrians. ${ }^{1-4}$ In particular, increased numbers of light truck vehicles (LTVs) have introduced new challenges for pedestrian safety. This is true in much of Europe and Japan, as well as in some developing countries. However, it is especially a problem in the United States, where two thirds of all LTVs are sold.

Although pedestrian injuries have decreased during the recent years, they remain a major health problem, accounting for $13 \%$ of traffic fatalities in the United States. ${ }^{6}$ In Europe, over 6000 pedestrian deaths per year occur. ${ }^{7}$ In Japan, pedestrian deaths have remained at around 2500 per year, comprising $27 \%-32 \%$ of traffic deaths. ${ }^{8}$ In efforts to improve upon this continued toll, the European Experimental Vehicles Committee Working Group 17, National Highway Traffic Safety Administration (NHTSA), the International Organization of Standardization, and the International Harmonization Research Activities pedestrian safety group have proposed a series of crash tests that evaluate a vehicle's safety for the pedestrians. ${ }^{6-11}$

Experimental tests with cadavers and dummies can answer many questions regarding pedestrian collisions. However, due to the dynamic nature of the crash, many important biomechanical aspects, such as vehicle-pedestrian interaction, cannot be evaluated in such experimental studies. In order to better understand how pedestrian injuries are influenced by changes in vehicle design, in depth studies of real world crashes are necessary. To evaluate the impact of the aforementioned changes on the characteristics of pedestrian injuries, we used data from the Pedestrian Crash Data Study (PCDS), conducted by NHTSA from 1994 to $1998 .^{23}$ We evaluated the hypothesis that the risk of severe injury and death is higher for pedestrians hit by LTVs or vans compared with those struck by passenger vehicles.

\section{METHODS}

From 1994 to 1998, 552 pedestrian injuries were recorded in the PCDS in six cities: Buffalo, Chicago, Dallas, Fort Lauderdale, San Antonio, and Seattle. The sites were selected based on the availability of applicable pedestrian crashes. ${ }^{12}$ Complete methodology of the study has been previously reported. ${ }^{12}$ A brief summary of the methodology is given here.

A pedestrian was defined as any person who was on a traffic way or on a sidewalk or path contiguous with a traffic way or on private property. Persons in or on a non-motorist conveyance, such as bicycle or horseback, were excluded from this study. ${ }^{12}$ Each crash should have met certain other criteria. First the vehicle had to be moving forward and the pedestrian should not have been lying or sitting at the time of the crash. Second, only passenger vehicles, light trucks, and vans made after 1990 were included. Some special old models of vehicles like Ford Taurus (1988-89) that had front design similar to newer vehicles were also eligible. Third, the striking portion of the vehicle should have been forward of the A pillar, with original manufactured parts and without modification or any previous damage. Finally, the pedestrian impacts should have been the vehicle's only impacts.

After notification of a pedestrian crash, principally by police radio, the research team went to the scene of the crash. After determining the general conformity of the crash to the previously mentioned criteria, the data gathering process was started at the scene. If a pedestrian, or an individual familiar with the crash event in the case of a mortality, could not be located or interviewed, or if the vehicle damage

Abbreviations: AIS, abbreviated injury scale; $\mathrm{Cl}$, confidence interval; ISS, injury severity score; LTV, light truck vehicle; NHTSA, National Highway Traffic Safety Administration; PCDS, Pedestrian Crash Data Study 
measurements could not be obtained within 24 hours of the crash, the case was dropped from the study.

From 144 variables regarding crash, vehicle, and pedestrian characteristics recorded in PCDS, we used the following: pedestrian age and sex, class of vehicle, initial point of impact, impact speed, abbreviated injury scale (AIS), ${ }^{13}$ pattern of injury, vehicle curb weight, and outcome. Injury severity score (ISS) was calculated from AIS.

Since children have reached more than $90 \%$ of their adult height by age 14, we used this age as the cut off for adults compared to children. ${ }^{14}$ Vehicles were categorized as passenger vehicles, vans, and LTVs. LTVs included compact and large utility vehicles $(\leqslant 4500 \mathrm{~kg})$ and light conventional trucks $(\leqslant 4500 \mathrm{~kg})$. Vans comprised both mini-vans and full size vans $(\leqslant 4500 \mathrm{~kg}) .{ }^{12}$ Site of principal injury was defined as the body region with the highest AIS score. In those cases with the same AIS score in different body regions, the following priority was used for defining the site of the principal injury: head-neck-face $>$ thorax $>$ abdomen $>$ spine $>$ lower extremity>upper extremity. ${ }^{16}{ }^{17}$

Student's $t$ test was used to compare continuous variables and $\chi^{2}$ was used for categorical variables. When appropriate, logistic regression was used to adjust for age and impact speed. ${ }^{18}$

\section{RESULTS}

From 552 recorded cases, no injury was reported in nine cases and in one case the number and severity of the injury were not recorded. These cases were excluded from analysis. From 542 cases available for analysis, $82 \%$ of all injuries were caused by frontal collisions. Ten percent of the pedestrians were hit by the right and $8 \%$ by the left side of the vehicle. Sixty nine percent of the collisions were related to passenger vehicles, $18 \%$ to LTVs, and $13 \%$ to vans.

\section{Injury severity score}

Adults struck by LTVs had a higher risk of moderate injury (ISS $\geqslant 9)(56 \%)$ than those struck by either passenger vehicles $(44 \%)$ or vans $(33 \%) \quad(p=0.023) \quad$ (table 1$)$. In children, the small sample size precluded firm conclusions regarding effects of vehicle class on injury severity. Risk of moderate injury for children was $50 \%$ for vans, $28 \%$ for passenger vehicles, and $19 \%$ for LTVs $(p=0.18)$. Similar patterns were observed when ISS $\geqslant 15$ was used as the cut off for severe injury for adults $(p=0.021)$ and children $(\mathrm{p}=0.14)$.

Table 1 Distribution of the patients based on the injury severity score (ISS), age group, and class of vehicle; values are number (\%)

\begin{tabular}{llll}
\hline $\begin{array}{llll}\text { Vehicle class/age } \\
\text { category }\end{array}$ & ISS & & \\
\cline { 2 - 3 } & $\mathbf{1 - 8}$ & $\mathbf{9 - 7 5}$ & Total \\
\hline $\begin{array}{l}\text { Passenger vehicle } \\
\text { Children }\end{array}$ & $62(72)$ & $24(28)$ & 86 \\
$\quad$ Adults & $161(56)$ & $125(44)$ & 286 \\
$\quad$ Total & $223(60)$ & $149(40)$ & 372 \\
LTV & & & \\
$\quad$ Children & $13(81)$ & $3(19)$ & 16 \\
$\quad$ Adults & $36(44)$ & $46(56)$ & 82 \\
$\quad$ Total & $49(50)$ & $49(50)$ & 98 \\
$\begin{array}{l}\text { Van } \\
\text { Children }\end{array}$ & $6(50)$ & $6(50)$ & 12 \\
$\quad$ Adults & $40(67)$ & $20(33)$ & 60 \\
$\quad$ Total & $46(64)$ & $26(36)$ & 72 \\
Total & & & \\
$\quad$ Children & $81(71)$ & $33(29)$ & 114 \\
$\quad \begin{array}{l}\text { Adult } \\
\text { Total }\end{array}$ & $237(55)$ & $191(45)$ & 428 \\
\hline
\end{tabular}

\section{Abbreviated injury scale}

As presented in table 2 , considering maximum AIS $\geqslant 4$ as the level of the severe injuries, adult pedestrians struck by LTVs had a higher risk of severe injury (33\%) than those struck by either passenger vehicles $(21 \%)$ or vans $(22 \%)(p=0.074)$. Again, small sample size in children made the interpretation of the results difficult. Nine percent of the children in passenger vehicle crashes (eight children), $6 \%$ in LTV crashes (one child), and $17 \%$ of children struck by vans (two cases) had severe injuries $(p=0.637)$. Analysis using maximum AIS $\geqslant 3$ as a cut off showed similar results for adults $(p=0.02)$ and children $(\mathrm{p}=0.217)$.

\section{Site of principal injury}

Head-neck-face was the major injured body region in $42 \%$ of the patients. Lower extremities (35\%), thorax (7\%), upper extremity $(7 \%)$, spine $(7 \%)$, and abdomen $(2 \%)$ were ranked as the second to sixth. The distribution of the site of principal injury for children and adults is presented figs 1 and 2 .

Frequency of head-neck-face injuries in children varied slightly by vehicle type: $51 \%$ for passenger vehicles, $44 \%$ for LTVs, and $17 \%$ for van crashes $(p=0.078)$. Lower extremity injuries, the second most common injury, occurred with different frequency depending on the vehicle type: $30 \%$ of passenger vehicles, $44 \%$ of LTVs, and $67 \%$ of van crashes $(p=0.038)$. In adults there was no difference among LTVs, vans, and passenger vehicles in pattern of injury $(\mathrm{p}=0.794)$.

\section{Outcome}

As depicted in table 3, mortality rate was higher for LTVs $(25 \%)$ compared with passenger vehicles $(12 \%)$ or vans $(6 \%)$ $(p<0.001)$. This was principally because of the higher rate of mortality among adults struck by LTVs. Furthermore, in all classes of vehicles, adults had higher mortality rate than children. Again small sample size has made generalization to the overall pediatric population difficult.

\section{Potentially confounding variables}

Patients in the LTV group had higher mean (SD) age (39 (24) years) than those in the passenger vehicle ( 33 (22) years) and van (36 (21) years) groups $(\mathrm{p}=0.039)$.

Mean (SD) impact speed was higher for LTVs (30 (24) $\mathrm{km} / \mathrm{h})$ and passenger vehicles $(29(20) \mathrm{km} / \mathrm{h})$ than vans $(22$ (16) $\mathrm{km} / \mathrm{h})(\mathrm{p}=0.025)$. Distribution of the male sex was not different for passenger vehicles (53\% female), LTVs (53\%), and vans $(47 \%)(\mathrm{p}=0.618)$.

Table 2 Distribution of the patients based on the maximum abbreviated injury scale (AIS), age group, and class of vehicle; values are number (\%)

\begin{tabular}{|c|c|c|c|}
\hline \multirow{2}{*}{$\begin{array}{l}\text { Vehicle class/age } \\
\text { category }\end{array}$} & \multicolumn{2}{|l|}{ AIS } & \multirow[b]{2}{*}{ Total } \\
\hline & $1-3$ & $4-6$ & \\
\hline \multicolumn{4}{|l|}{ Passenger vehicle } \\
\hline Children & $78(91)$ & $8(9)$ & 86 \\
\hline Adults & $226(79)$ & $60(21)$ & 286 \\
\hline Total & 304 (82) & 68 (18) & 372 \\
\hline \multicolumn{4}{|l|}{ LTV } \\
\hline Children & $15(94)$ & $1(6)$ & 16 \\
\hline Adults & 55 (67) & 27 (33) & 82 \\
\hline Total & $70(71)$ & $28(29)$ & 98 \\
\hline \multicolumn{4}{|l|}{ Van } \\
\hline Children & $10(83)$ & $2(17)$ & 12 \\
\hline Adults & 47 (78) & $13(22)$ & 60 \\
\hline Total & $57(79)$ & $15(21)$ & 72 \\
\hline \multicolumn{4}{|l|}{ Total } \\
\hline Children & $103(90)$ & $11(10)$ & $114(21)$ \\
\hline Adults & 328 (77) & $100(23)$ & $428(79)$ \\
\hline Total & $431(80)$ & $111(20)$ & $542(100)$ \\
\hline
\end{tabular}


Table 3 Pedestrian crash mortality rate based on the age group and class of vehicle; values are number (\%)

\begin{tabular}{|c|c|c|c|}
\hline \multirow{2}{*}{$\begin{array}{l}\text { Vehicle class/ } \\
\text { pedestrian age } \\
\text { category }\end{array}$} & \multicolumn{2}{|l|}{ Outcome } & \multirow[b]{2}{*}{ Total } \\
\hline & Alive & Dead* & \\
\hline \multicolumn{4}{|l|}{ Passenger vehicle } \\
\hline Children & $81(94)$ & $5(6)$ & $86(100)$ \\
\hline Adults & $246(86)$ & 40 (14) & $286(100)$ \\
\hline Total & 327 (88) & 45 (12) & 372 (100) \\
\hline \multicolumn{4}{|l|}{ LTV } \\
\hline Children & 16 (100) & - & $16(100)$ \\
\hline Adults & 58 (71) & $24(29)$ & $82(100)$ \\
\hline Total & 74 (75) & $24(25)$ & 98 (100) \\
\hline \multicolumn{4}{|l|}{ Van } \\
\hline Children & $12(100)$ & - & 12 (100) \\
\hline Adults & $56(93)$ & $4(7)$ & $60(100)$ \\
\hline Total & $68(94)$ & $4(6)$ & 72 (100) \\
\hline \multicolumn{4}{|l|}{ Total } \\
\hline Children & $109(96)$ & $5(4)$ & $114(100)$ \\
\hline Adults & 360 (84) & $68(16)$ & 428 (100) \\
\hline Total & 469 (87) & 73 (13) & $542(100)$ \\
\hline
\end{tabular}

\section{Multivariate analysis}

To have a realistic estimate of the effect of the vehicle type on the severity of the injury and mortality rate, multivariate analysis was used to adjust for potentially confounding variables, including impact speed and age. As sex of the pedestrians was equally distributed among different classes of vehicle we did not consider it as a potentially confounding variable.

Table 4 presents the odds ratio for ISS $\geqslant 9$ for LTVs and vans in comparison to passenger vehicles, after adjustment for impact speed and age, as ordinal variables. The odds of ISS $\geqslant 9$ for LTVs was $1.8(\mathrm{p}=0.051)$ and for vans was 1.5 $(p=0.241)$. Considering impact speed and age as continuous variables in the model, decreased the odds of ISS $\geqslant 9$ for LTVs to $1.5(\mathrm{p}=0.211)$ and for vans to $1.4(\mathrm{p}=0.341)$.

Similar analysis using ISS $\geqslant 15$ as the level of the severe injury showed that pedestrians struck by LTVs were 2.1 times more at risk of severe injury $(\mathrm{p}=0.021)$. The odds of severe injury (ISS $\geqslant 15$ ) for vans was 1.6 (95\% confidence interval (CI) 0.76 to $3.57, \mathrm{p}=0.207$ ).

Table 5 presents the odds ratio for maximum AIS $\geqslant 4$ for LTVs and vans compared to passenger vehicles and after adjustment for impact speed and age, as ordinal variables. The odds of maximum AIS $\geqslant 4$ for LTVs was $2.98(p=0.004)$ and for vans was $3.0(p=0.013)$. Considering age and impact speed as continuous variables in the regression model, the odds ratio of maximum AIS $\geqslant 4$ for LTVs decreased to 2.1 $(p=0.055)$ and for vans increased to $3.2(p=0.009)$.

Similar analysis using maximum AIS $\geqslant 3$ as the level of the severe injuries showed that the odds ratio of severe injuries for LTVs was $1.92(p=0.035)$ and for vans $1.26(p=0.526)$.

As mentioned before, crash mortality rate was the major outcome variable in this study. As shown in table 6 and after adjustment for age and impact speed as ordinal variables, the risk of death for LTVs was 3.4 (95\% CI 1.45 to 7.81 ). Our data did not show any considerable difference in risk of death between van-involved collisions and passenger vehiclepedestrian crashes (odds ratio 0.57, p =0.42). Larger sample size was needed to detect small differences in risk of death between van and passenger vehicle-involved collisions, if such a difference really existed. The increased mortality associated with LTVs did not change materially when different statistical models were used, including models in which age and impact speed were formatted as continuous or ordinal variables.

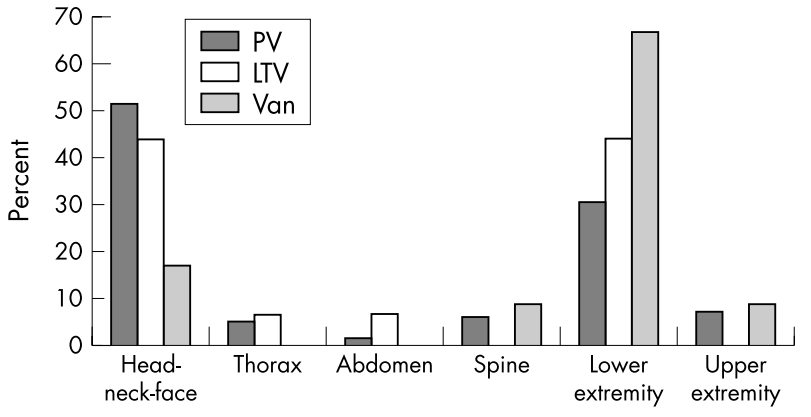

Figure 1 Sites of principal injury in patients younger than 14 years old (LTV, light truck vehicle; PV, passenger vehicle).

No significant change in the major results of this study was observed when the van group was restricted to mini-vans only (data not shown).

\section{Curb weight}

In spite of the importance of vehicle curb weight in vehiclevehicle collisions, curb weight is generally not considered a determinant of injury severity in vehicle-pedestrian crashes due to the overwhelming discrepancy in the masses of the pedestrians compared with almost any vehicle. However as this issue has been raised in few other studies, ${ }^{19}{ }^{20}$ we performed a supplemental analysis adding curb weight to the final model. After adjustment for curb weight, pedestrian age and impact speed, the odds ratio for risk of death for pedestrians struck by LTVs increased to 4.0 (95\% CI 1.45 to $11.05, \mathrm{p}=0.007$ ), while changes in the curb weight itself was not associated with a significant change in the risk of death (odds ratio $0.996, \mathrm{p}=0.54$ ).

\section{DISCUSSION}

In LTV-passenger vehicle crashes, passenger vehicle passengers suffer more severe injuries in the head, neck, and thorax. This has been attributed to the larger mass and higher bumper height of LTVs. $^{21}$ Similar studies in pedestrian crashes are scarce and most data are from dummy and cadaver studies. The interpretability of these studies has been limited by their inability to account for the dynamic nature of pedestrian crashes. Thus data from real world crashes are needed.

There are two major sources for data on real world pedestrian crashes. Police reports usually detail information about the time and place of the collision, type of vehicle, and major outcome, such as death. Hospital records mainly include information about medical condition and treatment. Neither of these two data sources routinely describes the probable mechanism of injury.

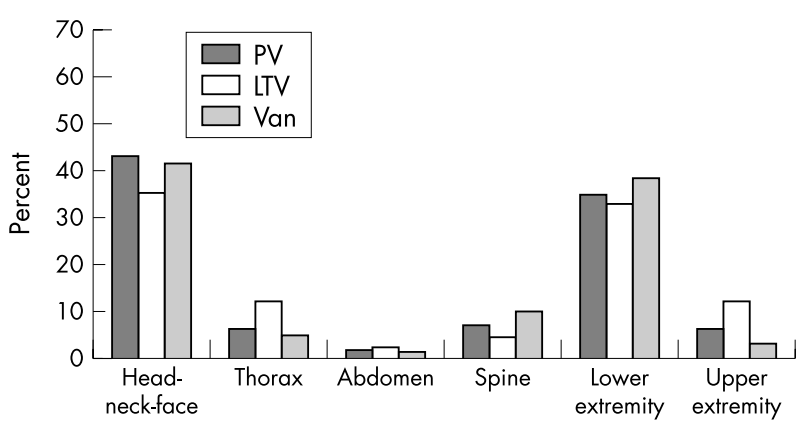

Figure 2 Sites of principal injury in patients 14 years or older (LTV, light truck vehicle; PV, passenger vehicle). 
Table 4 Multivariate logistic regression analysis to evaluate the effect of class of vehicle on risk of injury severity score (ISS) $\geqslant 9^{*} \dagger$

\begin{tabular}{|c|c|c|c|}
\hline & $\begin{array}{l}\text { Odds ratio of } \\
\text { ISS } \geqslant 9\end{array}$ & $\begin{array}{l}95 \% \\
\text { Confidence } \\
\text { interval }\end{array}$ & p Value \\
\hline \multicolumn{4}{|l|}{ Vehicle class } \\
\hline Passenger vehicle & Reference & - & - \\
\hline LTV & 1.8 & 0.99 to 3.34 & 0.05 \\
\hline Van & 1.5 & 0.76 to 3.04 & 0.24 \\
\hline \multicolumn{4}{|l|}{$\begin{array}{l}\text { Speed category } \\
(\mathrm{km} / \mathrm{h})\end{array}$} \\
\hline$\leqslant 20$ & Reference & - & - \\
\hline $21-30$ & 2.8 & 1.5 to 5.2 & 0.001 \\
\hline $31-40$ & 9.5 & 5.0 to 17.9 & $<0.0001$ \\
\hline $41-50$ & 15.3 & 6.6 to 35.7 & $<0.0001$ \\
\hline$>50$ & 55.5 & 21.6 to 142.4 & $<0.0001$ \\
\hline \multicolumn{4}{|l|}{ Age category } \\
\hline Children & Reference & - & - \\
\hline Adults & 1.5 & 0.8 to 2.7 & 0.15 \\
\hline
\end{tabular}

In the PCDS, the research teams have attempted to fill this gap by reconstructing pedestrian crashes, evaluating the chain of the events leading to the crash, and the etiology of injuries to specific body regions. Before discussing the major findings of this study, the limitations of the study methodology should be mentioned.

First, this study focused on passenger vehicles, LTVs, and vans. Pedestrians struck by other vehicles, such as buses and motorcycles, are not included. In 2001, more than 16\% of all pedestrian's fatalities in single vehicle crashes were related to the vehicles not considered in this study. ${ }^{22}$

Second, there were small numbers of pediatric cases in the PCDS. Several other studies evaluated pediatric driveway injuries in depth. ${ }^{23-26}$ However the issue of the mechanisms of child pedestrian collisions outside driveways has not been well evaluated. In a few hospital based studies, there was not enough information regarding the crash characteristics. In order to answer the critical questions regarding the differences in children injury profile among passenger vehicle, LTV and van-involved collisions, further studies with larger sample size are required. In spite of these limitations, the PCDS provides a solid opportunity for researchers to evaluate the effects of vehicle front end design on pedestrian injuries.

In the PCDS, the risk of pedestrian death for LTVs was 3.4 times that for passenger vehicles. Other studies evaluating pedestrian mortality in real world crashes with different classes of vehicles are scarce. However, in general the literature corroborates the findings of the current study. Lefler and Gabler in an analysis of three data sets (Fatality Analysis Reporting System, General Estimates System, and PCDS) reported that one fourth of the large van-pedestrian crashes, one out of seven sport utility vehicle-pedestrian crashes, and one out of 20 passenger vehicle-pedestrian crashes result in death. ${ }^{47}$ Analysis of 217 mortality cases in Seattle during a six year period showed that $48 \%$ of all the fatalities were related to passenger vehicles, $17 \%$ to LTVs, and $11 \%$ to vans. However in that study nothing was mentioned about the risk of pedestrian death based on the striking vehicle..$^{28}$ Ballesteros et al evaluated 3368 pedestrian crashes in Maryland. They showed that mortality rate for sport utility vehicles was higher $(24.1 \%)$ than for passenger vehicles $(12.6 \%)$. They attributed this difference in mortality rate to higher speed limit in the area and larger mass of the sport utility vehicles. ${ }^{19}$ In our study, adding vehicle weight to the multivariate model showed that curb weight was not
Table 5 Multivariate logistic regression analysis to evaluate the effect of class of vehicle on risk of maximum abbreviated injury scale (AIS) $\geqslant 4^{*} \dagger$

\begin{tabular}{|c|c|c|c|}
\hline & $\begin{array}{l}\text { Odds ratio of } \\
\text { AIS } \geqslant 4\end{array}$ & $\begin{array}{l}95 \% \\
\text { Confidence } \\
\text { interval }\end{array}$ & p Value \\
\hline \multicolumn{4}{|l|}{ Vehicle class } \\
\hline Passenger vehicle & Reference & - & - \\
\hline LTV & 2.9 & 1.4 to 6.3 & 0.004 \\
\hline Van & 3.0 & 1.3 to 7.3 & 0.01 \\
\hline \multicolumn{4}{|l|}{$\begin{array}{l}\text { Speed category } \\
(\mathrm{km} / \mathrm{h})\end{array}$} \\
\hline$\leqslant 20$ & Reference & - & - \\
\hline $21-30$ & 1.33 & 0.4 to 4.1 & 0.62 \\
\hline $31-40$ & 6.31 & 2.7 to 18.9 & $<0.0001$ \\
\hline $41-50$ & 7.63 & 2.8 to 20.6 & $<0.0001$ \\
\hline$>50$ & 64.37 & 26.1 to 158.5 & $<0.0001$ \\
\hline \multicolumn{4}{|l|}{ Age category } \\
\hline Children & Reference & - & - \\
\hline Adults & 1.3 & 0.6 to 29 & 0.52 \\
\hline \multicolumn{4}{|c|}{$\begin{array}{l}\text { *Analysis performed on } 451 \text { cases with sufficient data for variables in the } \\
\text { analysis. } \\
\text { †Affer adjustment for impact speed and age as ordinal categorical } \\
\text { variables. }\end{array}$} \\
\hline
\end{tabular}

associated with risk of death and that adjustment for it did not change the risk of death for LTVs compared with passenger vehicles. Mizuno and Kajzar evaluated the effect of the vehicle weight on pedestrians' outcome. ${ }^{20}$ They showed that the geometrical incompatibility of LTVs is the major cause of this higher mortality rate among pedestrians and not the vehicle weight. Risk of moderate injuries (ISS $\geqslant 9$ ) in adults was higher for LTVs (50\%) than for passenger vehicles $(40 \%)$ or vans $(36 \%)$, even after adjustment for impact speed and pedestrians' age. However in the Maryland study, adjustment for speed limit in the area of collision and for vehicle weight eliminated observed differences. ${ }^{19}$

Evaluation of the trajectory of the pedestrian crashes might explain the findings of these studies. In a frontal adultvehicle collision, the vehicle bumper contacts the pedestrian, and the chain of other events mainly depends on the pedestrian's height. In passenger vehicles, the bumper contacts the lower extremity below the center of gravity of the pedestrian. Consequently, the leading edge of the hood strikes the proximal lower limb or pelvis and finally the upper torso and head hit the top surface of the bonnet or windshield. After this "wrap and carry", the pedestrian and

Table 6 Multivariate logistic regression analysis to evaluate the effect of class of vehicle on pedestrian crash mortality ${ }^{*}+$

\begin{tabular}{|c|c|c|c|}
\hline & $\begin{array}{l}\text { Odds ratio of } \\
\text { pedestrian death }\end{array}$ & $\begin{array}{l}95 \% \\
\text { Confidence } \\
\text { interval }\end{array}$ & p Value \\
\hline \multicolumn{4}{|l|}{ Vehicle class } \\
\hline Passenger & Reference & - & - \\
\hline LTV & 3.4 & 1.4 to 7.8 & 0.005 \\
\hline Van & 0.6 & 0.1 to 2.2 & 0.417 \\
\hline \multicolumn{4}{|c|}{$\begin{array}{l}\text { Speed category } \\
(\mathrm{km} / \mathrm{h})\end{array}$} \\
\hline$\leqslant 20$ & Reference & - & - \\
\hline $21-30$ & 0.8 & 0.08 to 8.0 & 0.857 \\
\hline $31-40$ & 17.9 & 4.8 to 66.2 & $<0.0001$ \\
\hline $41-50$ & 75.0 & 20.7 to 271.9 & 0.001 \\
\hline$>50$ & 83.3 & 22.6 to 306.9 & $<0.0001$ \\
\hline \multicolumn{4}{|l|}{ Age category } \\
\hline Children & Reference & - & - \\
\hline Adults & 1.6 & 0.6 to 7.7 & $<0.0001$ \\
\hline
\end{tabular}

*Analysis performed on 451 cases with sufficient data for variables in the analysis.

†After adjustment for impact speed and age as ordinal categorical. 


\section{Key points}

- The number of LTVs has increased considerably in most developed countries, especially in the United States.

- Two thirds of the LTVs of the world are sold in the United States.

- The change in vehicle fleet has been associated with significant changes in pedestrian injury profile.

- Only real world crash studies, such as those in PCDS, are able to evaluate the dynamic nature of pedestrian injuries.

- LTVs were associated with 3.0 times higher risk of severe injuries in comparison with passenger vehicles.

- Risk of death in LTV-pedestrian collisions is 3.4 times that of passenger vehicle-pedestrian crashes.

- Vehicle front end design, especially for LTVs, should be considered in future motor vehicle safety standards.

vehicle travel at the same speed until the subsequent braking of the vehicle leads to forward movement of the pedestrian when the vehicle stops. Eventual contact of the pedestrian with the ground often produces further injuries. Taller vehicles like LTVs hit a pedestrian above his/her center of gravity. In this case, the pedestrian will not wrap around the vehicle, but will project forward, and it is more probable that he/she will be run over by the vehicle. ${ }^{11}$

For children, because of their shorter stature, the chance of being hit above the center of gravity is higher. This can explain the higher proportion of children projected forward while struck by passenger vehicles (35\%) and LTVs $(90 \%)$ compared with adults hit by passenger vehicles (18\%) and LTVs (53\%) in front collisions (data not shown).

Evaluation of issues such as the effect of pedestrian's body position before crash, pedestrian pre-crash movement, and vehicle-pedestrian interaction on the type and severity of injury need further study. However existing data are in support of the importance of technical tests to evaluate vehicle safety not only for passengers but also for pedestrians. ${ }^{29}{ }^{30}$ Such technical tests should take into account the findings of real world crashes.

\section{CONCLUSION}

For pedestrians, the severity of the injury and the injury pattern varies dramatically with vehicle design. Our study shows that, after adjusting for impact speed and pedestrian age, the probability of death for pedestrians struck by LTVs was significantly higher than for those struck by passenger vehicles. Therefore, with the rapid increase in the number of different types of light truck vehicles, the threat to pedestrian safety is on the rise. These data suggest the need to consider vehicle front end design, especially for LTVs, in motor vehicle safety standards.

\section{ACKNOWLEDGEMENTS}

This study was funded in part by a grant from the Crash Injury Research and Engineering Network (CIREN) of the National Highway Traffic Safety Administration (NHTSA). The published material represents the position of the authors and not necessarily that of DOT/NHTSA.

\section{Authors' affiliations}

B S Roudsari, C N Mock, R Kaufman, D Grossman, Harborview Injury Prevention and Research Center, Seattle, Washington

B Y Henary, J Crandall, Center for Applied Biomechanics, University of Virginia, Charlottesville, Virginia

\section{REFERENCES}

1 Chidester AB, Isenberg RA. Final report. The Pedestrian Crash Data Study, Report No 248. Washington, DC: National Highway Traffic Safety Administration, 2001

2 Isenberg R, Chidester C, Mavros S. Update on the Pedestrian Crash Data Study PCDS. Windsor, Canada, June 1998. 16th Enhanced Safety of Vehicles (ESV) 1998:1212-23

3 Jarrett K, Saul R. Pedestrian injury: analysis of the PCDS Field Collision Data. Windsor, Canada, June 1998. 16th Enhanced Safety of Vehicles (ESV) 1998:1204-23.

4 Lefler D, Gabler $\mathrm{H}$. The emerging threat of light truck impacts with pedestrians. Amsterdam, Netherlands, June 2001. 17th Enhanced Safety of Vehicles (ESV) 2001:1-6.

5 Bradsher K. The triumph of SUVs. High and mighty. 1st Ed. New York: Public Affairs, 2001:382-412.

6 Stammen J, Saul R, Ko B. Pedestrian head impact testing and PCDS reconstructions. Amsterdam, Netherlands, June 2001. 17th Enhanced Safety of Vehicles (ESV) 2001:1-9.

7 Department of the Environment, Transport and the Regions. UK official accident statistics. Report No 459/transport. London: DETR, 1998

8 Matsui $Y$, Wittek A, Konosu A. Comparison of pedestrian subsystem safety tests using impactors and full-scale dummy tests. Automotive crash researchside impact, rollover and vehicle aggressivity. SAE 1671. Warrendale, PA: Society of Automotive Engineers, 2002:39-54.

9 MacLaughlin T, Kessler JW. Pedestrian head impact against the central hood of motor vehicles - test procedure and results. 34th STAPP Car Crash Conference Proceedings. Warrendale, PA: Society of Automotive Engineers, 1990: 113-121.

10 Han $Y$, Lee $Y$. Optimization of bumper structure for pedestrian lower leg impact. Impact biomechanics. SAE SP-1666. Warrendale, PA: Society of Automotive Engineers, 2002:63-70

11 Crandall JR, Bhalla KS, Madeley NJ. Designing road vehicles for pedestrian protection. BMJ 2002;324:1145-8.

12 National Highway Traffic Safety Administration. National Accident Sampling System. Pedestrian Crash Data Study. 1994 Data collection, coding, and editing manual. Washington, DC: US Department of Transportation, NHTSA, 1994

13 Association for the Advancement of Automotive Medicine. Abbreviated injury scale-1990 revision. Des Plains, IL: AAAM, 1990.

14 Needlman RD. The second year. In: Behrman RE, Kliegman RM, Jenson HB, eds. Nelson textbook of pediatrics. 16th Ed. Philadelphia: WB Saunders, 2000:39-41.

15 Siberry GK. Growth charts. In: Siberry GK, lannone R, eds. The Harriet Lane handbook. 5th Ed. St Louis: Mosby, 2000:288-91.

16 MacKenzie EJ, Shapiro S, Moody M, et al. Functional recovery and medical costs of trauma: an analysis by type and severity of injury. J Trauma 1988;28:281-97

17 Mock CN, Adzotor KE, Conklin E, et al. Trauma outcomes in the rural developing world: comparison with an urban level I trauma center. J Trauma 1993;35:518-23.

18 Rosner B. Fundamentals of biostatistics. 5th Ed. Pacific Grove: Duxbury, 2000.

19 Ballesteros MF, Dischinger PC, Langenberg P. Pedestrian injuries and vehicle type in Maryland, 1995-1999. Accid Anal Prev 2003;927:1-9.

20 Mizuno K, Kajzer J. Compatibility problems in frontal, side single ca collisions and car-to-pedestrian accidents in Japan. Accid Anal Prev 1998:31:381-91.

21 Siegel JH, Loo G, Dischinger PC, et al. Factors influencing the patterns of injuries and outcomes in car versus car crashes compared to sport utility, van, or pick-up truck versus car crashes: Crash Injury Research Engineering Network Study. J Trauma 2001;51:975-90.

22 National Highway Traffic Safety Administration. Fatality Analysis Reporting System (FARS) web-based encyclopedia. Washington, DC: US Department of Transportation, NHTSA, 2002. Available at: http://www-fars.nhtsa.dot.gov (accessed 1 May 2003)

23 Nadler EP, Courcoulas AP, Gardner M, et al. Driveway injuries in children: risk factors, morbidity, and mortality. Pediatrics 2001;108:326-8.

24 Carter W. Driveway motor vehicle injuries in children. Med J Aust 2000;173:503.

25 Murphy F, White S, Morreau P. Driveway-related motor vehicle injuries in the paediatric population: a preventable tragedy. N Z Med J 2002; 115:U148.

26 Silen ML, Kokoska ER, Fendya DG, et al. Rollover injuries in residentia driveways: age-related patterns of injury. Pediatrics 1999;104(1):e7.

27 Lefler D, Gabler $\mathrm{H}$. The fatality and injury risk of light truck impacts with pedestrians in the United States. Accid Anal Prev 2003;949:1-10.

28 Harruff RC, Avery A, Alter-Pandya AS. Analysis of circumstances and injuries in 217 pedestrian traffic fatalities. Accid Anal Prev 1998;30:11-20.

29 European Enhanced Vehicle Safety Committee. EEVC Working Group 17 report. Improved test methods to evaluate pedestrian protection afforded by passenger cars. (December 1998 with September 2002 updates.) European Enhanced Vehicle Safety Committee, 2002:1-98. Available at: http:// www.eevc.org/publicdocs/WG17_Improved_test_methods_updated_ sept_2002.pdf (accessed 27 October 2003)

30 Ananova. New car safety standards to protect pedestrians and cyclists. Leeds, UK: Ananova, 2003. Available at: http://www.ananova.com/news/story/ sm_821929.html (accessed 27 October 2003). 